\title{
CONSIDERAÇÕES SOBRE A ESCRITA LACANIANA DOS DISCURSOS*
}

Júlio Eduardo de Castro

Doutor em Teoria
Psicanalítica pelo
Programa de
Pós-graduação em
Teoria Psicanalítica,
Instituto de
Psicologia/UFRJ;
psicanalista;
professor da
Universidade Federal
de São João del-Rei
(UFSJ).

Doutor em Teoria Psicanalítica pelo Programa de Pós-graduação em Teoria Psicanalítica, Instituto de Psicologia/UFRJ psicanalista; Universidade Federal (UFSJ)
RESUMO: A escrita lacaniana dos discursos é composta de elementos (letras), lugares (quadrantes) e funções (operadores lógicos). Cada um dos discursos formalizados por Lacan é composto pela distribuição peculiar dessas letras nesses lugares e funções. Lacan estabeleceu, desse modo, uma estrutura própria para cada um dos quatro discursos: o discurso psicanalítico, o discurso do mestre, o discurso histérico e o discurso universitário. Examinamos a construção lógica feita por Lacan - principalmente no Seminário 17, O avesso da psicanálise - para cada um desses discursos, ressaltando suas consistências, aproximações e contrastes. Pretende-se demonstrar como a devida consideração à teoria lacaniana dos discursos pode ser um importante meio de abordagem psicanalítica do sujeito por meio de seu universo discursivo.

Palavras-chave: Objeto a; discurso psicanalítico; discurso do mestre; discurso histérico; discurso universitário.

ABSTRACT: Considerations on the writing of Lacan's discourses. The writing of Lacan's discourses is made up of elements (letters), places (quadrants) and functions (logical operators). Each of these discourses formalized by Lacan is composed by the peculiar distribution of these letters in these places and functions. Lacan established, in this way, his own structure for each of the four discourses: the psychoanalytical discourse, the master discourse, the hysterical discourse and the university discourse. Lacan's logical construction was analyzed - mainly in Seminar 17, The contrary of the Psychoanalysis - for each of these discourses, highlighting their consistencies, approaches and contrasts. The purpose of this paper is to demonstrate how the appropriate consideration in Lacan's discourses can be an important psychoanalytical approach of the subject by means of its discursive universe.

Keywords: Object a, psychoanalytical discourse, master discourse, hysterical discourse, university discourse.

\footnotetext{
* O presente artigo foi escrito sobre alguns registros e desdobramentos feitos em minha Tese de Doutorado (CASTRO, 2006), particularmente no ponto em que ela tematiza a teoria lacaniana dos discursos.
} 
L acan formula sua teoria dos quatro discursos recorrendo à escrita algébrica. A estrutura de cada um dos quatro discursos nos é dada aí por um matema específico. Com o termo 'discurso', Lacan passou a designar quatro modos de estruturação do laço social — daquilo que, por meio do discurso, faz liame social. Essa estruturação do laço social é apresentada por meio da coordenação de quatro elementos - a, \$, S1, S2 — distribuídos em quatro lugares diferentes: o lugar do agente ou semblante, o lugar do trabalho ou Outro, o lugar da produção e o lugar da verdade. A rotação dessas quatro letras por cada um desses quatro lugares — mantida inalterada a sequência lógica das letras, ou seja, sem comutação possível — resulta em quatro matemas, um para cada discurso: o matema do discurso do mestre, o matema do discurso histérico, o matema do discurso universitário, o matema do discurso psicanalítico. Porém, antes de focalizar cada um desses matemas, situamos a seguir o Seminário 17: O avesso da psicanálise (LACAN, 1969-1970/1992), momento em que a formalização da teoria dos quatro discursos é, pela primeira vez, levada a esse lugar público, característico do ensino de Lacan: os seus Seminários.

\section{SITUANDO O SEMINÁRIO 17: O AVESSO DA PSICANÁLISE}

Neste Seminário, o ensino de Lacan reflete a relação de avesso - em termos topológicos e, se possível, matemizando essa relação - existente entre o discurso do mestre (e do inconsciente) e o discurso psicanalítico.

Durante a realização deste Seminário, o próprio Lacan não se cansava de ressaltar e anunciar que, nos seus Escritos, existia, desde 1966, a marca de seu projeto como envolvendo a retomada do projeto freudiano pelo avesso, além, é claro, de destacar o discurso psicanalítico $(a \rightarrow \$)$ como o que restou do trabalho sobre o inconsciente $(\mathrm{S} 1 \rightarrow \mathrm{S} 2$ ), levado a termo por um sujeito inicialmente ‘histericizado' em seu discurso $(\$ \rightarrow S 1)$. Virar Freud pelo avesso, pôr para fora o lado de dentro de sua teoria, implicou, concomitantemente, na realização de uma busca meticulosa, qual seja, a análise crítica da clínica freudiana, considerada em suas impossibilidades e em seus meandros.

Imbuído do espírito de que o inconsciente é um discurso $(\mathrm{S} 1 \rightarrow \mathrm{S} 2),{ }^{1}$ Lacan estabelece aí sua teoria dos quatro discursos. Sobre o fato de serem apenas quatro, ele esclarece, alguns anos mais tarde, serem três discursos que existem sobre o fundamento do discurso psicanalítico, discurso este que foi sempre, por ele, escrito em último lugar. Isto era feito, em seu ensino, pela seguinte razão: para Lacan, toda e qualquer mudança de discurso, portanto mudança de razão, trazia a iminência do discurso psicanalítico. E essa proximidade e mesmo precipitação do discurso psicanalítico a cada mudança, ou risco de mudança, discursiva, nos é

\footnotetext{
${ }^{1}$ Espírito expresso em aforismos como: 'O inconsciente é o discurso do Outro' e 'O inconsciente é estruturado como uma linguagem'.
} 
dada por sua estrutura elementar: o desejo, por meio de seu objeto-causa (a), em posição de agente/semblante e o saber (S2) posto no lugar da verdade (a/S2).

$\mathrm{O}$ avesso da psicanálise foi proferido em meio a um período de turbulência no campo universitário francês. Maio de 1968, como ficou conhecido, foi um movimento estudantil que questionou as instituições e o poder, bem como suas bases, dentre elas o próprio saber. O contexto universitário se impunha, então, como lugar privilegiado - e o estudante como função sintomática da cultura - para uma análise dos efeitos da ciência: as novas formas de manifestação e de tratamento do sintoma, as mudanças na configuração familiar tradicional, as novas formas de relação estabelecidas pelo trabalho/mercado moderno (o discurso do mestre moderno, nomeado por Lacan de 'discurso do capitalista') e, por fim, o surgimento da própria psicanálise como efeito indireto do discurso da ciência. Portanto, maio de 1968 foi um momento em que uma reflexão forçada se impôs a partir de um denominador comum surgido na cultura: as novas formas de fazer laço social.

Foi ainda um momento social em que algo acerca do declínio da função paterna se manifestava na forma de revolução na cultura dos a-studados — neologismo feito por Lacan para se referir ao estudante como objeto agido pelo saber $($ S2 $\rightarrow$ a), conforme escrito no matema do discurso universitário — revolução essa causada pelo mal-estar presente na vida contemporânea a nos revelar a dificuldade do homem moderno com o gozo em um mundo dominado pelo discurso da ciência e por seu 'cão de guarda', o discurso universitário. Em 1969, assistimos igualmente à eclosão de uma crise na Escola Freudiana de Paris em torno da questão do passe, do ensino, da transmissão e da própria estrutura da instituição psicanalítica.

Nesse mesmo Seminário, Lacan ainda nos faz lembrar que o discurso do mestre já havia sido esclarecido por Hegel, por meio da formalização teórica acerca da dialética do senhor e do escravo, e que isso teria efeitos para a cultura e, principalmente, para o capitalismo. Essa era uma das raízes, de cunho hegeliano, daquele movimento estudantil que questionava as instituições e seus saberes, em especial aqueles produzidos e difundidos pela universidade, uma vez que o lugar/função do mestre já havia sido teorizado pela letra hegeliana e a mais-valia contabilizada pela teoria marxista.

Todo esse Seminário foi feito sob a égide não mais de retornar a Freud e, sim, de ir além do mestre, além do pai simbólico freudiano, além dos ideais atribuídos ao ideal do eu e encarnados na figura do líder grupal. Tomar Freud pelo avesso significou, assim, algo a mais: atribuir parcialmente ao mestre de Viena o discurso do mestre, tanto em seu ensino quanto na criação da instituição psicanalítica nos moldes da IPA (International Psychoanalytical Association). Isto é verificável na segunda seção no Seminário em foco, intitulada "Para além do 
complexo de Édipo” (LACAN, 1969-1970/1992, p.79-132). Nessa seção é sugerida a aderência de Freud aos ideais do pai, do eu e da massa de psicanalistas que se constituía por meio da criação da IPA, aderência essa que, em parte, se justificava em função do pioneirismo decorrente da fundação de um novo campo de conhecimento e de investigação, a psicanálise. Freud se ocupava da difusão de suas ideias bem como da institucionalização da psicanálise e, para tal, não media esforços, adotando vez por outra o discurso do mestre, inclusive ao almejar a inclusão da psicanálise - em forma de disciplina universitária - nos cursos de medicina da época (FREUD, 1919 [1918]/1980).

Assim, o Freud fundador instituiu a psicanálise recorrendo, vez por outra, ao discurso do mestre, sobretudo em seu ensino e em sua própria concepção de ciência enquanto lugar contaminado pelo significante pai e derivados. Existe, por isso, segundo Lacan, um resto mítico do pai e do mestre dentro da concepção freudiana de ciência — resto esse evidenciado na pregnância ao modelo do Édipo, estruturalmente concebido para as psiconeuroses e entendido como 'saber com pretensão de verdade’. De modo que, para Lacan, o mito do Édipo foi uma redução freudiana ao modelo do pai simbólico sendo, por isso mesmo, incapaz de abordar algo mais amplo: "a estrutura que anima o discurso analítico frente ao gozo” ( $\rightarrow$ $\rightarrow$ ) [LACAN, 1969-1970/1992, cap. VII]. Para tal, Lacan reexamina os mitos freudianos de Édipo, de Moisés e do Pai da Horda Primeva, averiguando neles indícios de retorno do pai real excluído do discurso da ciência.

Esse contexto sugeria, posteriormente e com Lacan, a necessidade de criação de instrumentos que possibilitassem aos psicanalistas dar uma maior coerência e inteligibilidade aos fenômenos e questões com os quais se defrontavam em seu cotidiano clínico - invenção essa a ser diferenciada tanto da lógica na qual se fundamentava e funcionava a instituição universitária quanto dos modelos da ciência convencional. Diferenciar a lógica, a ética e o modus operandi da psicanálise em relação à universidade e à ciência é uma das lições, dentre muitas, que se pode tirar desse Seminário. Para tal, a escrita do discurso psicanalítico - enquanto inseparável das outras três — formalizava, ou seja, fornecia uma formulação lógica para que os psicanalistas pudessem elaborar, de forma estruturada, a clínica psicanalítica no mundo contemporâneo.

\section{A ESCRITA DOS DISCURSOS}

Uma advertência preliminar: após ter estabelecido uma escrita para cada um dos quatro discursos - por recurso à lógica — literalizando-os, Lacan acrescentou mais tarde que há, em todo e qualquer discurso, pontos de fuga, de escapada, ou seja, furos ${ }^{2}$ que dão sustentação real a cada um deles, uma espécie de, pa-

\footnotetext{
2 Furo é o termo utilizado por Lacan em RSI (LACAN, 1974-1975) com o objetivo de, se não topologizar sua teoria dos discursos, ao menos dela nos oferecer uma versão topológica. Daí
} 
rafraseando Freud, umbigo do discurso: "É por vazar (no sentido: tonel) que um discurso toma seu sentido, ou seja: por ser impossível calcular seus efeitos” (LACAN, 1973/2003, p.550).

Escrever os quatro discursos valendo-se, para tal, da lógica algébrica ${ }^{3}$ e visando à estrutura que determina as enunciações elementares produzidas pelo ser falante, foi, por conseguinte, o projeto lacaniano que culminou na realização do Seminário O avesso da psicanálise (LACAN, 1969-1970/1992).

Para tal, Lacan fez uso de recursos lógicos oriundos do campo da matemática, dentre eles o uso da letra — promovido pela álgebra matricial ${ }^{4}$ — e a teoria da permutação cíclica, ${ }^{5}$ também parte da álgebra moderna.

$\mathrm{Na}$ escrita desses discursos, Lacan lança mão de quatro letras (a: o objeto a, mais-gozar, condensador de gozo e causa-do-desejo; \$: o sujeito barrado pelo significante; S1: o significante-mestre, o sê-lo, o significante pelo qual os outros significantes são ordenados; $\mathbf{S} 2$ : o saber constituído enquanto cadeia significante), distribuídas em quatro lugares, divididos dois a dois ao modo de quadrantes e separados por duas barras - a barra (/) aqui cumpre a função de ser o sinal que estabelece a resistência à significação, ou seja, a operação do recalcamento. Para especificar cada um desses lugares de apreensão do efeito significante pelo sujeito (não nos esqueçamos que se trata de um esquema calcado na lógica quadripartito), Lacan constrói um índice de designação, dando a cada um deles os seguintes nomes:

1. agente ou poder ou semblante

4. verdade
2. Outro/outro, ou trabalho ou gozo

3. produção/perda ou mais-gozar

a equiparação da fuga do sentido ao furo como fundamento real dos nós. A trajetória do ensino de Lacan - dos discursos aos nós borromeanos — suscitou a máxima de que toda e qualquer modalidade discursiva começa em hiância e termina em escapada, em fuga.

3 Álgebra: "Parte da matemática que estuda as leis e processos formais de operações com entidades abstratas” (AURÉLIO, 2002). Partindo do sentido lato de álgebra, sem dúvida, a teoria dos discursos formula-se em termos algébricos, serve-se do raciocínio algébrico em sua maneira de atribuir, ao real, a letra. Contudo, Lacan se serve desse raciocínio, o algébrico, subvertendo as teorias-padrão da álgebra e seus empregos usuais. O mesmo se dá em relação ao grafo tetraédrico, mencionado em Radiofonia (LACAN, 1970/2003), em que Lacan suprimiu uma das flechas (DARMOND, 1994) para propor a dinâmica de um modelo topológico, com força de paradigma, inventado a partir da ideia de modalidades discursivas.

4 "Parte do cálculo matricial em que se investigam as propriedades e transformações das matrizes sobre as operações de soma, produto, combinação linear de linhas e colunas etc." (AURÉLIO, 2002).

${ }^{5}$ Em um conjunto ordenado, permutação, sem comutação, em que cada elemento é substituído pelo seu sucessor (quando o sentido é anti-horário) ou pelo seu antecessor (quando o sentido é horário) e o último pelo primeiro (quando o sentido é anti-horário) ou o primeiro pelo último (quando o sentido é horário); permutação circular; ciclo. 
Lacan ainda faz uso das setas de implicação ou conexão $(\rightarrow)$ para orientar o sentido da cadeia significante e do quarto de giro circular como operador da transformação de um discurso em outro, por progressão (sentido horário) ou por regressão (sentido anti-horário), possibilitando assim a circulação das letras, em permutação circular, sem comutação, por quatro lugares.

Como no discurso do mestre:

$$
\begin{aligned}
& \mathrm{S} 1 \\
& \$ \leftarrow \frac{\mathrm{S} 2}{\mathrm{a}}
\end{aligned}
$$

no discurso histérico:

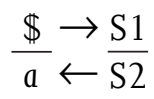

no discurso universitário:

$$
\frac{\mathrm{S} 2}{\mathrm{~S} 1} \leftarrow \frac{\mathrm{a}}{\$}
$$

e no discurso psicanalítico:

$$
\frac{\mathrm{a}}{\mathrm{S} 2} \underset{\mathrm{S} 1}{\stackrel{\$}{\mathrm{~S} 1}}
$$

O discurso do capitalista ${ }^{6}$ é obtido por efeito de uma torção feita sobre a banda esquerda no matema do discurso do mestre, sendo por isso uma variação desse mesmo discurso. O discurso do capitalista nos é então exposto pelo seguinte matema:

$$
\frac{\$}{\mathrm{~S} 1} \leftarrow \frac{\mathrm{S} 2}{\mathrm{a}}
$$

A escrita do discurso do capitalista, também chamado por Lacan de "discurso do mestre moderno", é feita ao tomá-lo como um derivado lógico do discurso do mestre por efeito da torção de sua banda lateral esquerda, ou seja: S1 e \$ são trocados de lugar, S1 passando do lugar de semblante ao lugar da verdade e o

\footnotetext{
${ }^{6}$ Segundo Darmon (1994, p.220), o discurso capitalista é por Lacan evocado "muito rapidamente em seu Seminário 17, descrevendo-o sem inscrevê-lo. A única escritura que dele fornece, tanto quanto eu saiba, ocorre em Milão, em 1972, na conferência sobre 'O discurso psicanalítico'”. Darmon nos esclarece que, com a teoria dos quatro discursos, "entramos em uma topologia elementar, a dos grafos, que encontra sua origem histórica na resolução, por Euler, do problema dos pontos de Koenigsberg. O grafo aqui em causa é o tetraédrico, pelo qual Lacan se interessa após o início de seus Seminários" (Idem, p.224).
} 
contrário ocorrendo com \$. Nesse discurso, a flecha da impotência, que parte da mais-valia (a) em direção ao significante-mestre (S1), indica-nos a sua própria superação, superação da impotência, promovida pela escrita marxista, em forma de quantificação-cotação, da mais-valia.

Observamos, por essa torção, que o significante-mestre (S1), no discurso do mestre, torna-se a verdade no discurso do capitalista, e que o sujeito (\$) é retirado de sua posição de verdade no discurso do mestre e posto, como no discurso do histérico, em posição de agente, ou seja, diante da cena do mercado como sujeito-consumidor. Portanto, há uma proximidade lógica do discurso capitalista ao discurso histérico, pela identidade do sujeito (\$) em posição de agente, e ainda uma proximidade lógica ao discurso universitário, pela identidade do significante-mestre (S1) em posição de verdade, ou seja, sob a barra.

Além desses lugares, letras, barras, setas e operadores, Lacan inclui ainda, nessa álgebra revolucionária, a impossibilidade - categoria aristotélica extraída da lógica modal - e a impotência, localizando cada uma delas em um lugar específico na estrutura matricial dos discursos, conforme nos é esclarecido principalmente em Radiofonia (LACAN, 1970/2003). Neste texto, Lacan inscreve a impossibilidade sobre e entre as barras, ou seja, entre os lugares ‘agente’ e ‘Outro'. A impossibilidade é aí escrita, em todos os discursos, como uma seta que parte do lugar do agente/ semblante em direção ao lugar do Outro/trabalho.

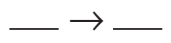

Assim, segundo Lacan, no discurso do mestre a impossibilidade está colocada entre o mestre (S1) e o saber (S2), indicando-nos assim a impossibilidade "de governar aquilo que não se domina”, a impossibilidade “de mandar no saber" (LACAN, 1969-1970/1992, p.445) e a impossibilidade "de fazer o seu mundo, do mestre, funcionar” (Idem, p.166). No discurso histérico, a impossibilidade está localizada entre o \$ e S1, a nos revelar a impossibilidade de o sujeito histérico dominar o significante-mestre. Em se tratando do discurso universitário, a impossibilidade está posta entre o saber (S2) e o objeto a, enquanto marca da impossibilidade de educar pelo comando do saber. Já no discurso psicanalítico, a impossibilidade está situada entre o objeto a e o sujeito $(\$)$, indicando-nos, assim, a impossibilidade de curar e mesmo de psicanalisar, e revelando-nos, ainda, a impossibilidade de abordagem do mais-gozar exclusivamente por apelo aos recursos do Outro. Entretanto, no discurso psicanalítico a impossibilidade é superada ao ser transmitida como e enquanto ato, ultrapassando, desse modo, o sujeito do significante em sua indeterminação.

O ato psicanalítico é uma aposta em que a impossibilidade seja feita letra. O ‘poder dos impossíveis' (LACAN, 1969-1970/1992, p.172-184), presente nas 
tarefas de governar/politizar/dominar, de educar/ensinar e de curar/psicanalisar estava, assim, escrito por meio do recurso ao matema. De modo que a escrita da impossibilidade - feita letra em cada um dos quatro discursos - indica-nos, na dimensão topológica, a localização e a inscrição do furo estrutural específico em cada um desses mesmos discursos: entre S1 e S2 (DM); entre \$ e S2 (DC); entre \$ e S1 (DH); entre S2 e a (DU); e entre a e \$ (DA).

Já a impotência é situada sob e entre as barras, ou seja, entre os lugares da produção-perda e da verdade, sendo escrita como seta que parte da produção em direção à verdade:

e que é, por Lacan, tida como uma proteção da verdade. ${ }^{7}$ No discurso universitário, sua localização está, então, entre o sujeito (\$) produzido e o seu reconhecimento no significante-mestre (S1), colocado no lugar da verdade. No discurso psicanalítico, a impotência é superada devido ao trabalho do psicanalisante de "saber haver-se com a verdade" (Ibidem, p.442). Portanto, nesse discurso, a impotência é ultrapassada pelo trabalho e pelo ato psicanalíticos, indicando-nos, por isso mesmo, uma transposição da produção de significantes-mestre (S1) para o saber (S2) em posição de verdade. Já no discurso do mestre, a impotência localizada entre o objeto a e o sujeito $(\$)$, mais especificamente, do objeto a ao sujeito - nos indica um furo estrutural desse discurso: não poder extrair, tanto do produto quanto da produção, qualquer verdade subjetiva. Desse modo, a impotência do discurso do mestre - escrita por Lacan em forma de seta localizada sob a barra, indo da produção da mais-valia (a) à verdade (\$) — é a escrita da alienação subjetiva característica desse discurso. ${ }^{8}$ No discurso do capitalista, o sujeito se coloca em cena e, dirigindo-se a um saber de mercado, portanto saber do Outro, tem por fim o gozo (em forma de consumo) de um objeto-mercadoria (bem, saber ou serviço), sendo, todavia, impotente em nele verificar, tal e qual no discurso universitário, a verdade de seu significante-mestre.

No discurso capitalista, o saber do trabalhador está, como no discurso do mestre, reduzido à condição de trabalho que gera mais-gozar — em forma de lucro para o capitalista e em forma de mais-gozar da mercadoria (S2/a) para o consumidor - porém, com a diferença de o sujeito estar colocado como dominante, diante da cena de consumo. Lacan inscreve aí uma mudança de posição do sujeito gerada, no discurso do mestre, pelo advento do capitalismo: o sujeito é

\footnotetext{
7 Isso aparece em enunciados como: "verdade, irmã da impotência" e "a impotência da verdade" (LACAN, 1969-1970/1992, p.166 e 156 respectivamente).

${ }^{8}$ O discurso do mestre promove a des-subjetivação do produto e da produção ao visar à extração da mais-valia.
} 
deslocado do lugar da verdade para o lugar do agente. E essa mudança de posição do sujeito, além das razões históricas ligadas ao advento do capitalismo, contou, ainda, com a influência do discurso histérico enquanto fiel contestador do gozo do mestre, principalmente por nele denunciar a impotência subjetiva $(\$ \leftarrow a)$ que subjaz em sua ânsia de domínio $(\mathrm{S} 1 \rightarrow \mathrm{S} 2)$.

Por isso, nos discursos histérico e capitalista há coincidência da posição do sujeito: nesses dois discursos, o sujeito (\$) está posicionado no lugar do semblante. Nesse sentido, o discurso histérico fez subjetivar, fez evoluir ${ }^{9}$ o discurso do mestre. Já a impotência no discurso histérico diz respeito à produção de saberes (S2) que, contudo, não dão conta do gozo - saberes nos quais o sujeito é incapaz de se verificar como/enquanto objeto mais-gozar $(a \leftarrow S 2)$. Por isso a alienação histérico-discursiva é, antes de tudo e paradoxalmente, uma alienação gozosa, fruto dessa impotência discursiva.

Uma das lições mais interessantes, extraída do seminário dedicado a $\mathrm{O}$ ato analítico (LACAN, 1967-1968) - seminário este realizado quase dois anos antes de O avesso da psicanálise (LACAN, 1969-1970/1992) — diz respeito à distinção elementar feita entre saber e verdade. Ao aproximar verdade ${ }^{10}$ e revelação mística, saber e construção significante, construção esta sempre sujeita às influências e engodos do eu, Lacan estabelece um importante diferencial clínico: o saber, subordinado que está ao gozo do sentido, é da ordem da construção significante, concerne, como se vê, ao significante e à interseção dos registros Simbólico e Imaginário; a verdade, por sua vez, diz respeito à revelação do real (R) por meio da queda do objeto a.

A verdade que diz respeito à psicanálise concerne, assim, ao mais-gozar. Lemos no matema do discurso psicanalítico 'o saber (S2) no lugar da verdade' e, ainda, - indo além da leitura usual de que o primeiro se coloca à prova da segunda - a existência de uma impossibilidade estrutural em tratá-los, S2 e V, como homólogos, sobretudo quando consideramos a fórmula estabelecida no título dado por Miller a uma seção do Seminário 17: O avesso da psicanálise — Saber, meio de gozo (LACAN, 1969-1970/1992, p.37). Nos matemas dos discursos, a verdade é um lugar, um quadrante protegido pela flecha da impotência que principia no lugar da produção. Já o saber, a letra S2, é o efeito da cadeia significante. De modo que o saber - é o que nos apontam os estudos e depoimentos sobre a finalização do tratamento psicanalítico - é sempre relativo ao gozo que o acompanha, o gozo transferencial ${ }^{11}$ (cf. a seção “Verdade, irmã de gozo”, idem, p.51). Em

\footnotetext{
${ }^{9}$ Evolução cuja notação nos é expressa pela transposição da barra pelo sujeito: de baixo (verdade) para cima (agente).

${ }^{10}$ Verdade essa sempre parcial (semi-dizer; meio-dizer) e marcada pela característica de ser essencialmente insuportável ao eu.

11 Permitimo-nos aqui conjugar esses dois termos — gozo e transferência — com a in-
} 
A ciência e a verdade (LACAN, 1966/1998), essa disjunção entre saber e verdade já se encontra nitidamente demarcada por Lacan, tendo sido a criação do conceito de objeto a o prenúncio dessa demarcação — objeto que, em seu ensino, se fez letra em punção (junção e disjunção) com o sujeito barrado pelo significante $(\$<>a)$. Desse modo, todos os quatro discursos têm como referente básico o lugar da verdade, ocupado por letras distintas em cada um deles, e sempre protegido pela impotência.

\section{AS PERSPECTIVAS DE MUDANÇA DE DISCURSO}

Examinados e cotejados, dois a dois, os discursos, à luz do conceito de inconsciente, trazem a possibilidade de progressão e de regressão. Progressão e regressão são modos de marcação de uma ocorrência capaz de causar mudança de discurso, ou seja, interferência estrutural de um discurso sobre outro. Em Radiofonia (LACAN, 1970/2003), as interferências mencionadas são as seguintes: 1) do discurso histérico sobre o discurso do mestre; 2) do discurso psicanalítico sobre o discurso universitário. Nos dois casos há a afirmação de que o primeiro discurso pode forçar alguma mudança sobre o segundo. Em se tratando do par ‘discurso do mestre' e 'discurso histérico', encontramos o seguinte:

“Assim, o discurso do mestre encontra sua razão pelo discurso da histérica, posto que, ao se fazer agente do onipotente, renuncia a responder como homem àquilo em que, ao lhe solicitar que o seja, a histérica obtém apenas saber. É ao saber do escravo que ele então recorre, por produzir o mais-de-gozar com o qual, a partir do seu (do seu saber), não conseguia que a mulher fosse causa de seu desejo (eu não disse objeto)" (LACAN, 1970/2003, p.445).

A partir dessa abertura de perspectiva — permitida pela possibilidade de interferência do discurso histérico sobre o discurso do mestre (escrita como progressão ou quarto de giro, no sentido horário, feito sobre o discurso do mestre), interferência essa feita pela contestação do lugar do sujeito, oculto sob

tenção de lembrar a existência de um resíduo do real pulsional, o objeto (a). Destacamos ainda que, na clínica psicanalítica, é esse objeto que permeia e mesmo sustenta, estrutural e subjetivamente, a demanda pela transferência de saber a um sujeito suposto ( $\rightarrow$ sss). Já desde a década de 1950, Lacan concebia a transferência como intimamente relacionada a um objeto privilegiado: "Em outras palavras, a transferência não é nada de real no sujeito senão o aparecimento, num momento de estagnação da dialética analítica, dos modos permanentes pelos quais ele constitui seus objetos" (LACAN: 1951/1998, p.224). Portanto, já era digna de notação a participação do mais-gozar na transferência: "Trata-se de uma escansão das estruturas em que, para o sujeito, a verdade se transmuta, e que não tocam apenas em sua compreensão das coisas, mas em sua própria posição como sujeito da qual seus objetos são função" (Idem, p.217). 
o significante-mestre $(\mathrm{S} 1 / \$)$, por meio da denúncia da impotência que lhe é inerente - indagamo-nos se algo similar poderia ocorrer, por regressão, em relação aos discursos psicanalítico e universitário. E em Lacan encontramos uma pista sobre como o discurso psicanalítico pode, se não provocar uma mudança de discurso, ao menos fazer ver a impotência característica do discurso universitário - qual seja: jamais incluir o furo no saber dito discursivo, nunca 'cavando um furo em seu próprio cálculo' — tamanha é sua fascinação pela completude do saber:

“Ao contrário, é por estar em progresso em relação ao discurso universitário que o discurso do analista pode permitir-lhe circunscrever o real de que sua impossibilidade exerce a função, supondo-se que ele queira submeter à questão do mais-degozar, que já tem num saber sua verdade, a passagem do sujeito ao significante do mestre. Isso é supor o saber da estrutura que, no discurso do analista, ocupa o lugar da verdade. O que equivale a dizer da desconfiança com que esse discurso tem que sustentar tudo o que se apresenta nesse lugar. Porque a impotência não é o disfarce do qual o impossível seria a verdade, mas tampouco é o contrário: a impotência serviria para fixar o olhar, se a verdade não se visse nela a ponto de ir ao êxtase. É preciso parar com essas brincadeiras, pelas quais a verdade paga o custo derrisório. É somente ao acuar o impossível em seu último reduto que a impotência adquire o poder de fazer o paciente transformar-se em agente. É assim que ela surge em ato em cada revolução com que a estrutura não tem a ver, para que a impotência mude de modalidade, é claro. Assim, a linguagem faz uma novação do que revela do gozo e faz surgir a fantasia que ele realiza por algum tempo. Ela só se aproxima do real à medida que o discurso reduz o dito a cavar um furo em seu cálculo. Desses discursos, no momento atual, não há aos montes.” (LACAN, 1970/2003, p.446)

Com essas palavras Lacan encerra Radiofonia. Abre-nos, com elas, uma perspectiva de que possa haver um abalo ou mesmo uma contestação, esclarecedora, do discurso universitário por meio do discurso psicanalítico. ‘Acuar o impossível’ do discurso universitário seria, então, tanto colocar em questão a posição do estudante (a) no lugar daquele que trabalha movido pelo saber, ou seja, sob a influência direta do Outro, quanto desconfiar dos saberes que aí o agenciam. É somente ao considerar a impossibilidade em seu 'último reduto' que o discurso psicanalítico supera a impotência que lhe é inerente e pode, por isso mesmo, circunscrever/escrever a impossibilidade característica do discurso universitário: a abordagem do maisgozar, do objeto-causa, por meio do saber $(\mathrm{S} 2 \rightarrow$ a). Por isso mesmo, o discurso universitário é esclarecido por seu 'progresso' no discurso psicanalítico.

Todavia, qualquer transmutação do discurso universitário sob os auspícios do discurso psicanalítico necessitaria — além da devida atenção à homologia 
estrutural existente nos discursos do mestre e do inconsciente $(\mathrm{S} 1 \rightarrow \mathrm{S} 2)$ - de uma 'histericização' do discurso enquanto índice de abertura à influência da psicanálise, ou seja, enquanto prenúncio do discurso psicanalítico. Como essa abertura seria feita? Por meio das revoluções da cultura, nos moldes do que ocorreu com os estudantes universitários em várias partes do mundo? Não cabe à psicanálise propor soluções de conciliação, ou de qualquer ordem, entre discursos distintos. Servir-se das contingências como meio de buscar a escrita de um discurso, o universitário, foi o que Lacan nos legou com sua teoria dos discursos. Ele se serviu da revolta dos estudantes ao tomá-la como contingência que surgiu justamente no meio das instituições dedicadas ao saber (universidades, Estado e instituições psicanalíticas), a leu como sintoma e formalizou algebricamente daí algo de sua escrita. De modo que 'histericizar' o discurso universitário seria algo que dependeria não apenas da admissão de furos nesse discurso, mas, sobretudo, do surgimento de algum mal-estar gerador de crise, subjetiva e cultural.

Extrapolando os objetivos desse artigo, apontamos outras duas possibilidades, além das já mencionadas, de mudança ou ao menos de interferência estrutural de um discurso sobre o outro: do discurso psicanalítico sobre o discurso histérico (situação freudiana clássica); do discurso histérico sobre o discurso universitário (situação a ser investigada pela pesquisa futura).

Entretanto, ao compararmos os matemas dos quatro discursos, notamos a posição de inverso em que se encontram os discursos universitário e histérico, apostando, assim, no confronto, gerador de mal-estar, que o discurso histérico pode causar não apenas ao discurso do mestre, denunciando os seus furos, mas, ainda, ao discurso universitário. Ao considerarmos que qualquer mudança de discurso traz a precipitação do discurso psicanalítico (sob o signo do amor de transferência), e não necessariamente a sua instalação, concebemos o discurso histérico como um poderoso estimulante subjetivo $(\$ \rightarrow$ S1) ao deslocamento discursivo, ou seja, como estímulo ao deslocamento do saber em posição de agente $(\mathrm{S} 2 \rightarrow$ a) que tanto caracteriza o discurso universitário. A escrita inversa desses dois discursos - o histérico e o universitário - indica a existência de um nicho de pesquisa, assim como ocorreu, a partir de Lacan, com a escrita envessa dos discursos do mestre e psicanalítico.

\section{CONSIDERAÇÕES FINAIS}

A teoria lacaniana dos discursos - em especial por sua escrita em forma algébrica, cuja finalidade principal consistiu em simplificar e resolver, por meio de fórmulas, problemas nos quais as grandezas são representadas por símbolos - nos ajuda a estruturar a clínica psicanalítica no mundo contemporâneo pelo que se segue. Além de nos permitir a generalização a partir de manifestações 
particulares, a escrita algébrica dos discursos tem o seguinte efeito imediato: a função descola-se do personagem. Tomar o universo como sendo antes de tudo discursivo, ou seja, estruturado como linguagem, porém através de um discurso prevalente, destaca lugares e funções em uso pelo sujeito que faz liame social. De modo que abordar o sujeito pelo viés discursivo por ele utilizado, no mínimo permite ao psicanalista a feitura de uma hipótese diagnóstica desligada de qualquer preocupação meramente taxonômica e, assim, dedicar-se ao que lhe compete. Sem a influência de ideologias - que em geral encharcam as nosografias, seus usos e leituras — o psicanalista terá como deter-se naquilo que lhe é pertinente: a condução do tratamento.

Outro aspecto relevante da teoria lacaniana dos discursos é sua abertura a mudanças de posição do sujeito que deles faz uso. Além da importância dada ao discurso histérico — tido por Lacan como condição indispensável à entrada do sujeito em análise, favorecendo assim sua mudança para o discurso psicanalítico — assinalamos, na seção anterior, outras perspectivas de mudança ou ao menos de influência/interferência de cada um dos discursos sobre os demais. E essa possibilidade de mudança apontou para a participação das funções (representadas pelas letras), dos lugares (representados pelos quadrantes), das relações (representadas pelas setas de implicação e barras) e de um operador (representado pelo quarto de giro que marca qualquer mudança de discurso) na estrutura subjetiva.

Recebido em 17/12/2007. Aprovado em 11/8/2008.

\section{REFERÊNCIAS}

AURÉLIO et al. (2002) Dicionário da língua portuguesa. Versão eletrônicodigital.

CASTRO, J. E. (2006). "Consequências éticas da teoria lacaniana dos discursos no ensino da psicanálise”. Tese de Doutorado. Rio de Janeiro: UFRJ — PPG em Teoria Psicanalítica.

DARMON, M. (1984) Ensaios sobre a topologia lacaniana. Porto Alegre: Artes Médicas.

FREUD, S. (1919[1918]/1980) “Sobre o ensino da psicanálise nas universidades”, in Edição standard das obras psicológicas completas de Sigmund Freud. Rio de Janeiro: Imago, v. XVII, p.217-224.

LACAN, J. (1951/1998) “Intervenção sobre a transferência”, in Escritos. Rio de Janeiro, Jorge Zahar, p.214-225. (1966/1998) “A ciência e a verdade”, in Escritos. Rio de Janeiro, Jorge Zahar, p.869-892. 
(1967-1968) O Seminário livro 15: O ato psicanalítico. Versão anônima, sem data.

. (1969-1970/1992) O Seminário livro 17: O avesso da psicanálise. Rio de Janeiro: Jorge Zahar.

(1970/2003) "Radiofonia", in Outros Escritos. Rio de Janeiro: Jorge Zahar, p.400-447.

(1971-1972/1981) O saber do psicanalista. Versão anônima em português.

(1973/2003) "Introdução à edição alemã de um primeiro volume dos Escritos”, in Outros escritos. Rio de Janeiro: Jorge Zahar, p. 550-556.

(1974-1975) O Seminário livro 22: RSI. Versão anônima em francês e português, sem data.

LAURENT, E. (1992) Lacan y los discursos. Buenos Aires: Manantial.

MILlER, J. A. O último ensino de Lacan, Opção lacaniana, n. 35. São Paulo, Eólia, jan. 2005, p.6-24.

Júlio Eduardo de Castro

julioecastro@mgconecta.com.br 